\title{
The Role of Apartments Interior Design on Individual Privacy: Residential Buildings in Erbil as a Case Study
}

\author{
Alan M. Qaradaxi ${ }^{1}$, Hafedh A. Yahya ${ }^{1,2, *}$ \\ ${ }^{1}$ College of Engineering, Tishk International University, Iraq \\ ${ }^{2}$ College of Engineering, University of Mosul, Iraq
}

Received October 15, 2021; Revised January 15, 2022; Accepted February 8, 2022

\section{Cite This Paper in the following Citation Styles}

(a): [1] Alan M. Qaradaxi, Hafedh A. Yahya, "The Role of Apartments Interior Design on Individual Privacy: Residential Buildings in Erbil as a Case Study," Civil Engineering and Architecture, Vol. 10, No. 2, pp. 669-681, 2022. DOI: $10.13189 /$ cea.2022.100222.

(b): Alan M. Qaradaxi, Hafedh A. Yahya (2022). The Role of Apartments Interior Design on Individual Privacy: Residential Buildings in Erbil as a Case Study. Civil Engineering and Architecture, 10(2), 669-681. DOI: 10.13189/cea.2022.100222.

Copyright $\bigcirc 2022$ by authors, all rights reserved. Authors agree that this article remains permanently open access under the terms of the Creative Commons Attribution License 4.0 International License

\begin{abstract}
Privacy refers to the control of how much information about an individual should be allowed into the public domain. Individual privacy in an apartment building refers to the blockage of information within an individual room within the family apartment. Previous studies have given less attention on the privacy of residential apartments which this study focuses on. This research paper aims to explore the role of interior design in providing individual privacy in residential buildings. With time, more demand for apartment buildings is experienced and people are preferring more private places as physical connections become rare. As such, the question of how to maintain individual privacy with the population increase and reduced need for physical connections prompted the study. To assess the interior design privacy of the apartments, an observational case study was applied. Eight residential buildings in Erbil formed the research sample and they were assessed using a Likert scale to obtain average values of each variable. The findings show that interior design elements tend to influence visual and acoustical privacy to a great extent. The choice of the interior design materials has an impact on the overall rating of building on protecting both acoustical and visual privacy. Results show no correlation between visual and acoustical privacy for the individual for the same project. The interior design of Shahan city apartment presents the worst regarding to individual privacy. The study concludes that in order to increase the value of housing unit, it should maintain the individual privacy within the limitations of the societies. It is recommended that privacy achieved by controlling
\end{abstract}

architectural elements of interior design of the apartment should raise its value. It is also recommended that the local and national governments strengthen policies regulating interior designs norms to reduce the lack of individual privacy.

Keywords Apartments, Visual Privacy, Acoustical Privacy Individual Privacy, Interior Design

\section{Introduction}

\subsection{Study Background}

Privacy refers to the control of how much information about an individual should be allowed into the public domain [1]. Individual privacy in an apartment building, refers to the blockage of information within an individual room within the family apartment. Parents, for instance, need privacy from the children, be it their personal discussion or any other activities done within their rooms. On the other hand, each family member has his own privacy in somehow. The interior design of each home controls the amount of information that is retained within inner spaces. This way, two forms of privacy are significant when it comes to individual privacy within an apartment. One of them is acoustical privacy which has to do with having proper installations in place to control the sound passing from one space to another [2]. This protects 
confidential and sensitive information among the family members. The other one is visual privacy which is controlled through several barriers such as doors, windows, and walls [3].

Previous studies have given less attention on the privacy of residential apartments which this study focuses on. The study aims at assessing various apartment buildings for elements which contribute to individual privacy. The researcher examines the individual privacy of residential buildings of multi families and explores the impact of interior design on individual privacy.

Over time, privacy has become a human need and it is an element in Abraham Maslow's Hierarchy of Needs which is grouped into 5 categories; physiological, safety, belonging, self-esteem, and self-actualization [4]. Out of these levels, only two are closely related to privacy. One of them is self-esteem which is contributed by higher confidence levels by gaining privacy. Another one is self-actualization where people in this level have a higher degree of solitude and autonomy where they crave for privacy and personal freedom. As such, people tend to maintain private spaces for the sake of self-esteem and autonomy at the individual level. Some researchers, therefore, have tried to describe individual privacy in different ways.

\subsection{Problem Statement and Research Novelty}

During the past century, according to the communications and cultural changes around the world, Erbilian architecture has changed as well. The problem is that local users still need their cultural privacy due to their religious beliefs. However, because of the shrinkage of today's apartments, privacy is taken for granted. The uniqueness of the current research study is grounded on the fact that it assesses Erbilian apartments buildings according to two types of individual privacy level which are visual and acoustical privacy. Taking a look at the reviewed literature which was obtained from the best possible search term combination for the research, it can be seen that none of the articles has assessed Erbilian, Kurdish, or Iraqi apartment buildings. Only one of the studies, [3], has assessed the visual privacy in a Muslim community. As such, the research adds to the body of knowledge concerning individual privacy in buildings around Erbil and beyond. This research will be relevant in an area whereby the population is growing every day. Assessing how the individual privacy provides a different perspective for the designers and architects to see buildings from a different perspective according to individual Erbilians requirements of the $21^{\text {st }}$ century.

\section{Literature Review}

This chapter gives a highlight of previous research on knowledge about individual privacy in residential buildings in different geographical contexts especially among the Muslim communities. A review of the data collection sections helps in understanding the correct methodology to resort to and avoid an overload of the primary data collection. Also, reviewing the findings from the previous researchers helps in establishing a smooth transition and relevance of the topic across time.

M. M. Shabani, et al. [2] highlighted the two major types of privacy in their assessment of the Iranian contemporary compact apartment through flexible designing. The researchers recognize visual privacy as the most important type of privacy and it is followed by acoustical privacy. They justify the aspect of privacy by quoting several hadiths from the Qur'an which show the need for privacy especially for the Muslims. According to them, elements of acoustical privacy include acoustical installations for walls, roofs and floors. The other type of privacy identified and which is given less attention is spatial privacy and they do this while analyzing spatial arrangement in an Iranian setting. These findings are provided in the form of a literature review on how culture and religion influence the privacy in Iranian buildings.

A. N. Tomah, et al. [3] noted that building enclosures have psychological implications on individuals living inside. Their research analyzes the visual privacy in apartment buildings in Jordanian cities using Amman as a case study. The researchers reviewed various prototypes in Amman for 20 years. To determine the relationship between the house's size and privacy of the dwellers, the researchers analyzed the prototypes as a way of ascertaining their layouts and the allocation of the interiors within private and public zones. They then took the plans with the same layout to assess how they are influenced by privacy issues as well as the association between the building's privacy and interior space and how this association affects how the functional spaces within an apartment are designed. The results of the study show that the size of a building may not necessarily mean more privacy. In what the researchers call triple zones, a house is split into three zones; the private zone, the public zone, and the buffer zone. In a double zoned house, the house lacks a buffer zone which offers privacy as it divides the private and public zones. As such, privacy will be less in double-zoned houses despite the size. They conclude that Amman lacks regulations and relevant practices that govern designs to provide maximum privacy for the individuals.

S. Malik \& B. Mujahid [5] carried out research on typological analysis of house designs on residential buildings that had similar properties. The goal of this research was to find out how the Muslim culture influences design in Pakistan and Saudi Arabia. The researchers found out that although there are distinctive features across geographical locations, there are many similarities across all Muslim communities' building designs. To them privacy and comfort are the basic elements considered when building an Islamic home in any location. 
S. R. De Paris \& C. N. Lopes [6] talk about flexibility in housing which allows a person to live according to their own terms within an enclosure. Although the researchers do not directly cover individual privacy, they consider flexibility as an aspect which allows customization of privacy to meet individual needs. Customization translates into individual privacy for maintenance or blockage of information within an enclosure.

S. Javanshir [7] used descriptive- analytic to determine the existence of constructive privacy in apartment buildings and factors governing their creation. The method involved taking notes from the previous researchers while at the same time carrying out interviews which were analyzed through qualitative contents analysis technique. From the findings, the researchers conclude that over time, people's habits and expectations levels change over time, and building designs have to keep up with the trend. According to them, privacy is one of the evolving aspects of design and the new designers need to consider that while designing residential places of residence.

The issue of time deferences is also addressed. $\mathrm{H}$. Khamenehzadeh [8], assumed a qualitative strategy to analyze the realization of privacy in both modern and pre-modern houses in Iran. According to him, there are two types of privacy, individual and collective privacy, and they represent the ends of the privacy spectrum. They argue that in an Iranian setting, there is a weak unique personal identity in pre-modern buildings while it remains hard rare to find houses with collective privacy in modern buildings. They argue that a house should be able to bring together members of a family and provide minimal collective privacy while maximizing individual privacy.

J. Wahid \& F. Khozaei [9] also consider the issue of changing designs according to time with an aim of delineating the significance of visual privacy in an Iranian setting using Tehran as a case study. Some of the factors assessed in the article are the ones that affect visual privacy and they include balconies, entrances, openings, and layout. They found out that the traditional buildings in Tehran are made up of organically connecting buildings whose privacy is maintained by shared walls and public and private routes, maximizing social interaction while limiting interference with the household privacy. In modern day Iranian built environments, people are forced to draw curtains to keep their private spaces, making privacy one of the biggest architectural issues in the country.

\section{Methodology}

\subsection{Theoretical Framework}

The independent variables in this project were visual and acoustical privacy. In visual privacy, there are several factors affecting it such as windows and personal room doors. These elements were used in forming variables to be used in the study. The variables in visual privacy include location, transparency, height, and width of windows, and location and transparency of the door. Variables created from acoustical elements include insulation of walls, windows, doors, and ventilation openings.

\subsection{Method}

Case study design was used as a method of data collection. Case study is a qualitative technique detailing elements of a situation; in the current study, 8 apartment buildings in Erbil City were used as case studies to be observed by the researcher. The buildings to be included in the study are New Iskan towers, Shahan city, Naz city, Lana city, Atlantic city, Kurdistan city, 92 Apartments, and Kamarany apartments. They were selected because they have similar sizes. They are part of the city that have helped host a multiethnic family from many parts of the region, Iraq, Syria and other Middle Eastern countries. There are also people from European countries such as Turkey and all these people offer a good source of data because it is diversified. Although the researcher will not be directly talking to the residents, some constructions are a reflection of the cultural groups living in a particular area.

Therefore, diversified information can be gained regarding the apartments' privacy in the city using the 8 samples. The population for the study included all the apartment buildings in Erbil City to examine how well an apartment retains information for people inside the enclosure and blocks any sound coming from another room. A selection criterion was used to select the buildings to include in the study which helped avoid bias during sampling. The researcher used a two-phase technique referred to as double sampling. There 24 buildings selected for the first phase. In the second stage, the researcher selected buildings with the same characteristics to form the second sample and the total was 8 . Elements contributing to privacy such as walls, windows, floors, plans, and organization were assessed for each privacy level. The data collected here formed the primary data to be used in the research. This was backed up by the secondary data presented in the literature review.

A 3-point Likert scale was used to scale the privacy levels of the various building elements in every building at the individual privacy. Usually, 3-point scales have 2 options of agreeing or disagreeing to something, then a neutral option to form the third point. In this case, 0 represented low privacy, 1 represented medium privacy, and 2 represented high privacy.

As a way of ensuring ethical considerations are put into place, secondary sources used to support the primary data were succinctly cited in the research. Besides, while collecting primary data, the researcher made sure that the managers for every project assessed and respective residents were informed prior to entry into their premises to avoid conflicts. They were informed about the intention of the researcher and were required to sign a consent form as a confirmation that they allowed the researcher to examine 
their respective buildings.

This formula was used to calculate the Visual privacy $(\mathrm{Vp})$ for all different levels of the buildings.

$\mathrm{Vp}($ Visual Privacy) $=\mathrm{Vp}$ (Window) $+\mathrm{Vp}$ (Door) (1)

The following shows the acoustical privacy (Acp) for the apartment buildings.
Acp (Acoustical Privacy) $=\mathrm{A}($ Walls $)+\mathrm{A}($ Windows $)+$ $\mathrm{A}$ (Doors) + A (Ventilation Openings) (2)

Table 1 explains floor plan for all the 8 buildings selected for the study with short information about each one:

Table 1. Study samples

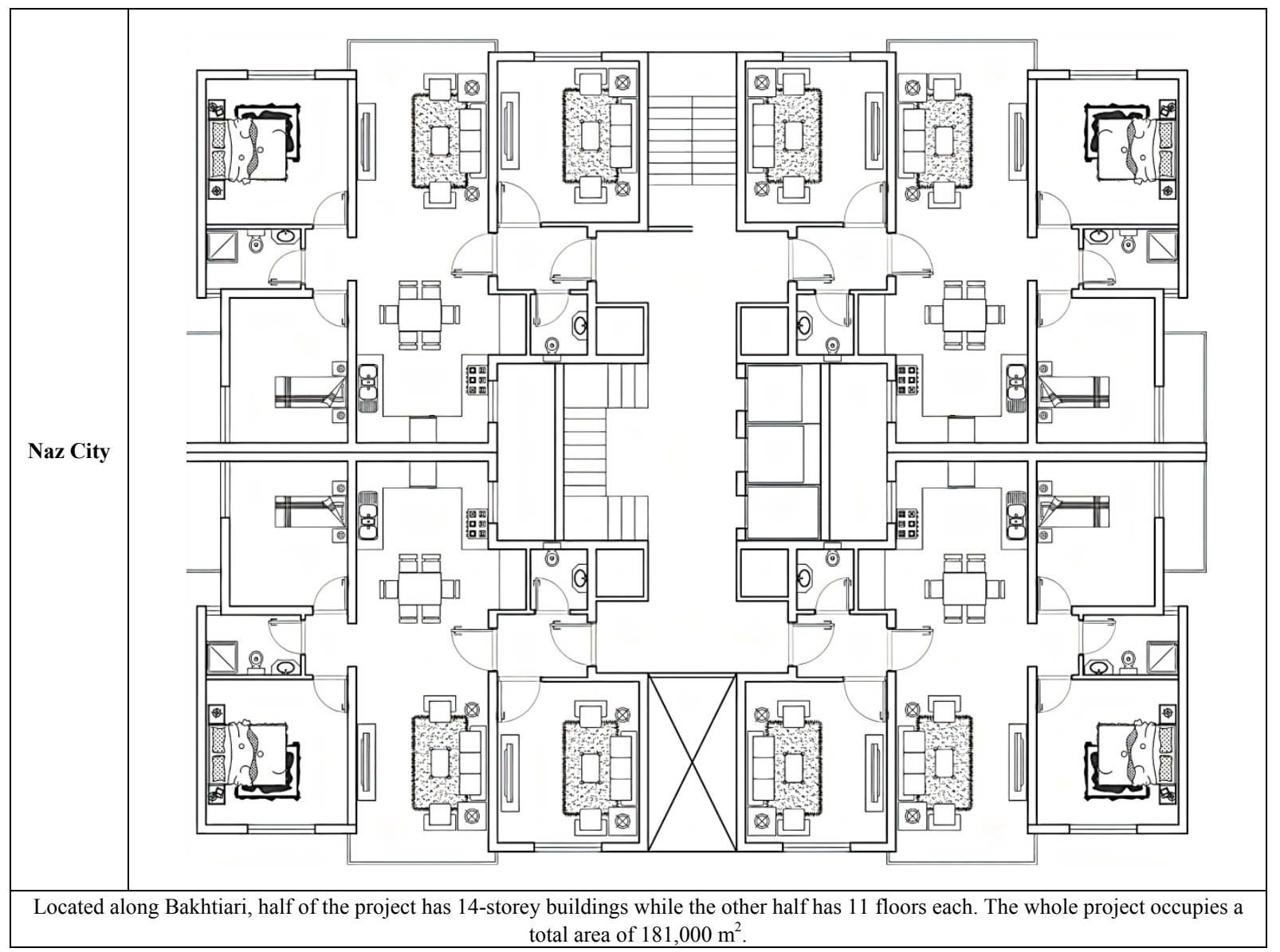




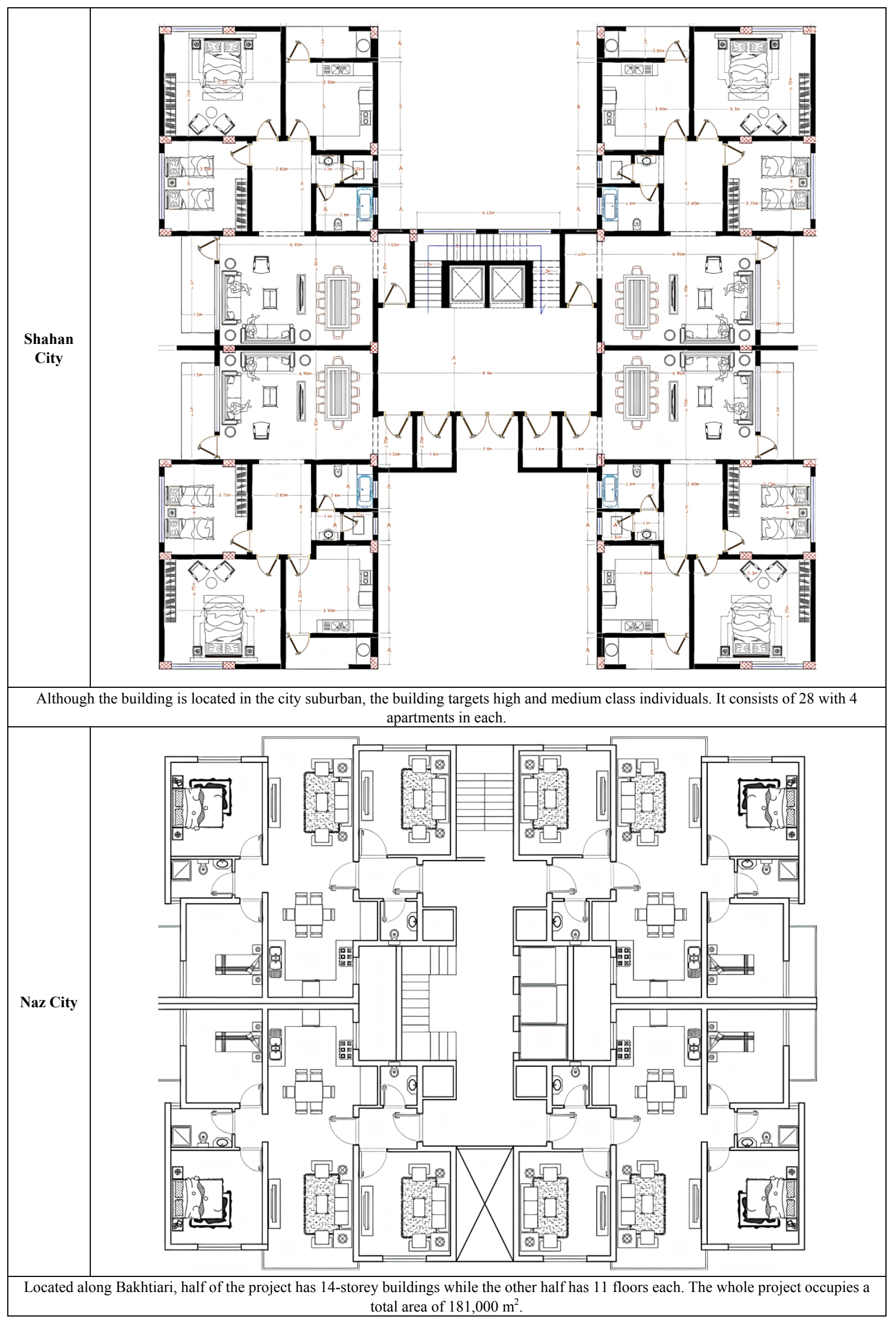




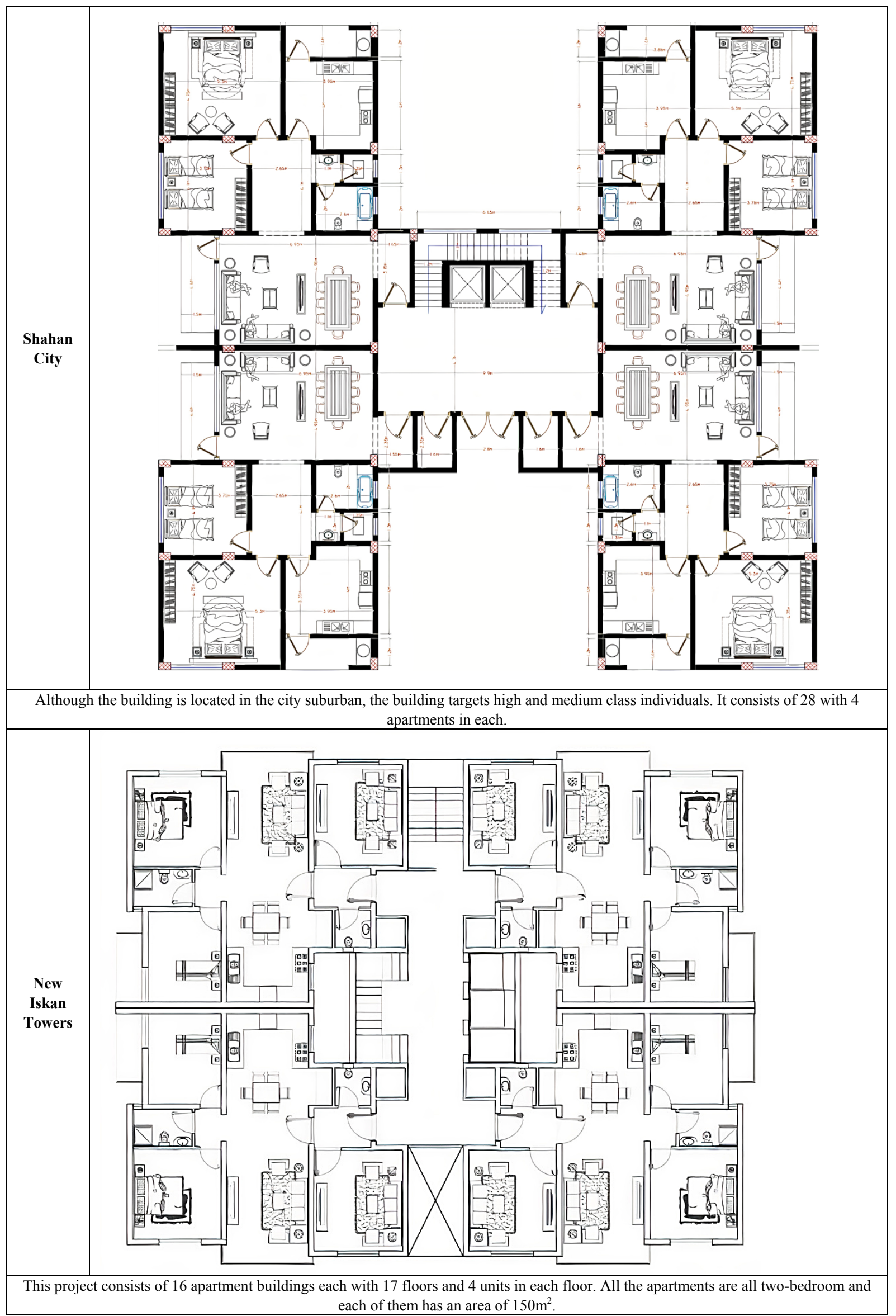




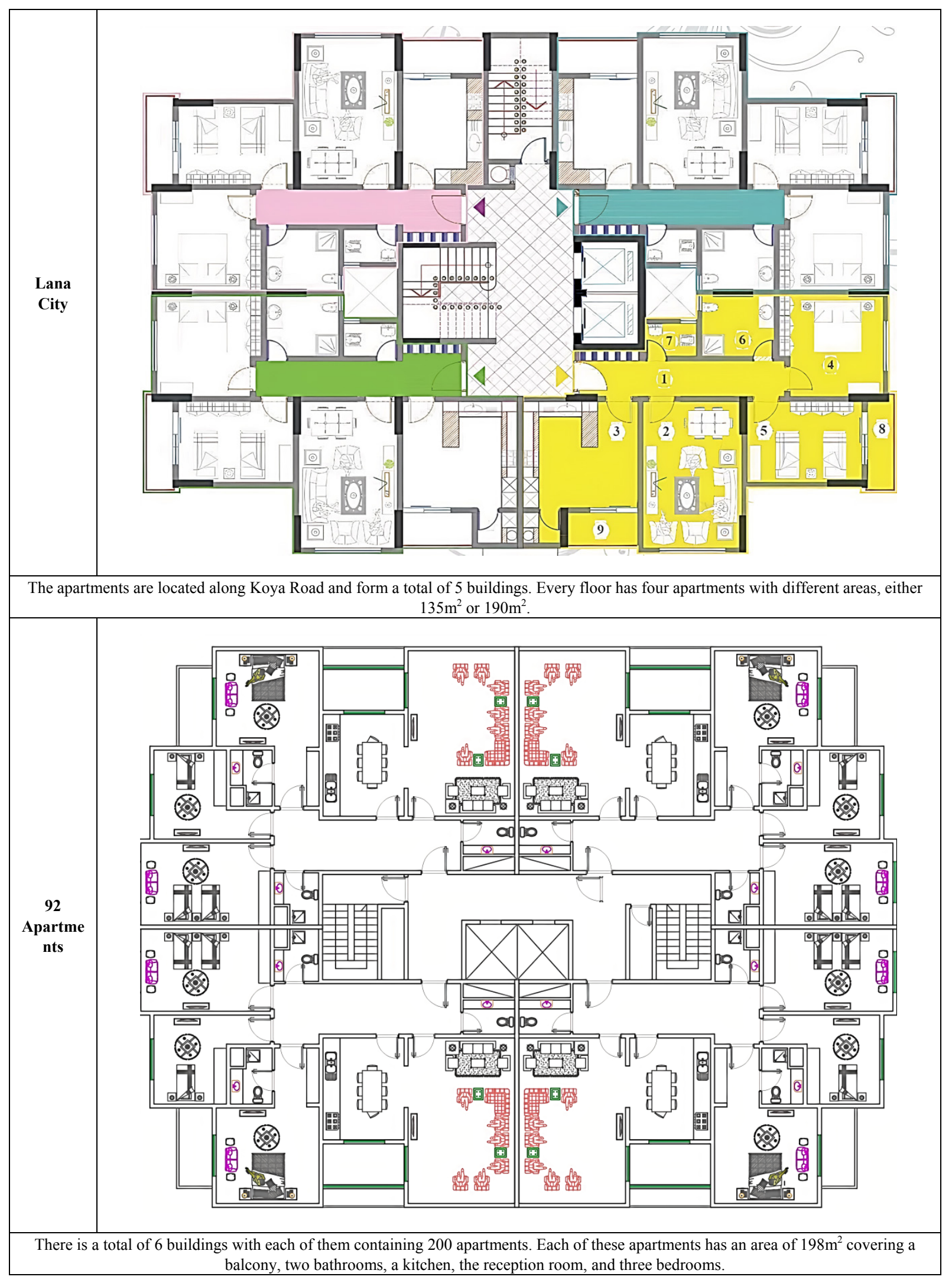




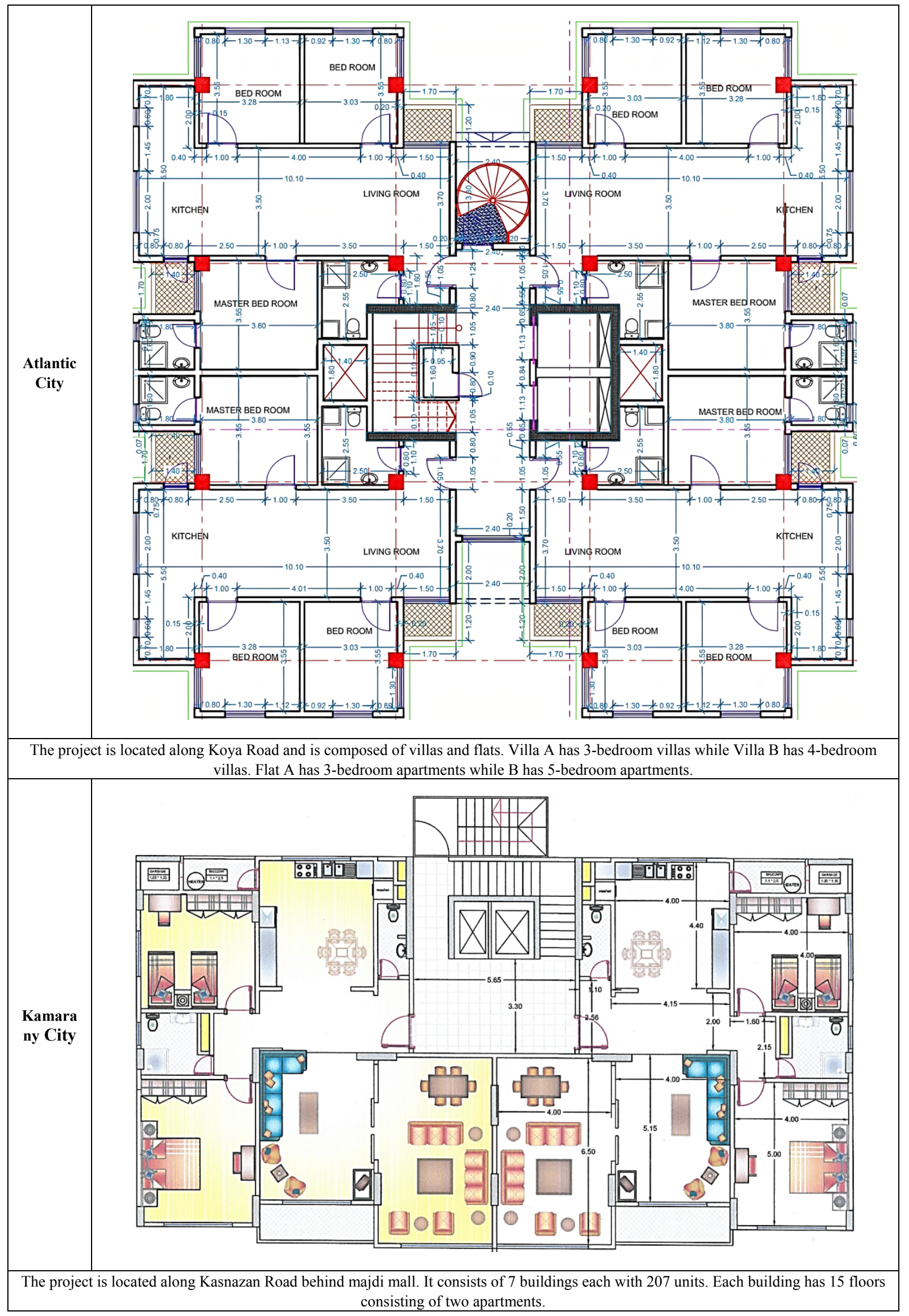




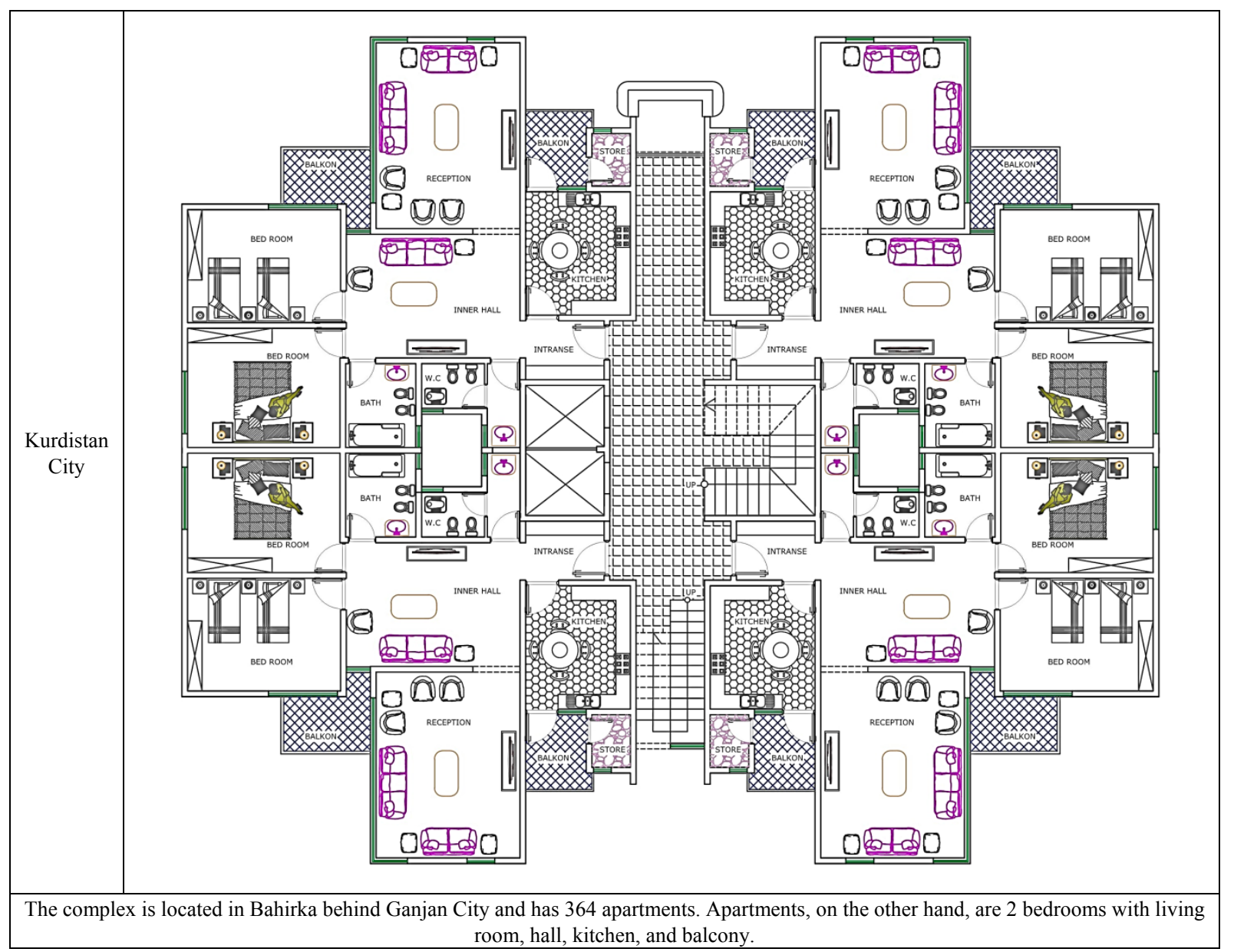

\section{Results and Discussion}

In this section, the results are presented for all the selected apartment buildings. After that, the researcher presents a discussion of these findings so as to come up with a cohesive conclusion and recommendations.

\subsection{Results}

\subsubsection{Visual Privacy}

Table 2 and Figure 1 show the results of the visual privacy of the two visual elements. The assessment of the two elements, windows and doors, for each of the apartment is presented.
Table 2. Visual privacy

\begin{tabular}{|c|c|c|}
\hline & Windows & Doors \\
\hline New Iskan Towers & 4 & 5 \\
\hline Shahan City & 0 & 2 \\
\hline Naz City & 5 & 6 \\
\hline Lana City & 2 & 4 \\
\hline Atlantic City & 1 & 5 \\
\hline Kurdistan City & 0 & 0 \\
\hline 92 Apartments & 2 & 6 \\
\hline Kamarany Apartments & 0 & 1 \\
\hline
\end{tabular}




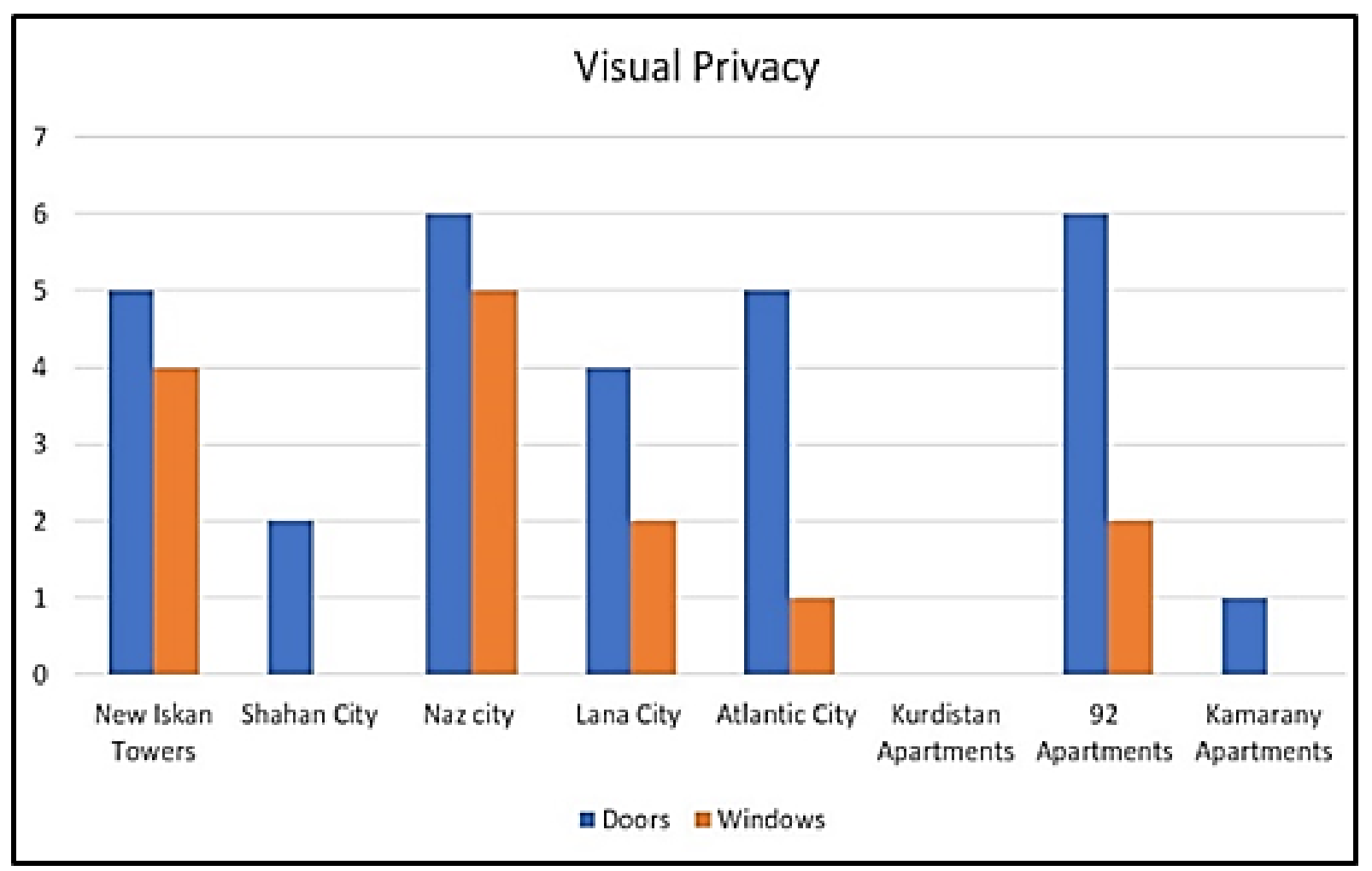

Figure 1. The results of visual privacy

Overall, the doors for all the apartment buildings have a better rating than the windows. From the chart, bars presenting the doors are longer than that of the windows for all the buildings, showing better ratings. For windows, Shahan City, Kurdistan City, and Kamarany Apartments had the least, scoring 0 in this category. Naz City scored the most with a rating of 5. For the doors, 92 Apartments and Naz City had the highest rating in this category, scoring 6 points while the least was Kurdistan City.

\subsubsection{Acoustical Privacy}

Elements of acoustical privacy for all the buildings were measured and presented. Table 3 and Figure 2 show the results of the acoustical privacy for each acoustical element selected.
Table 3. Acoustical privacy for each element

\begin{tabular}{|c|c|c|c|c|}
\hline & Walls & Windows & Door & Ventilation \\
\hline $\begin{array}{c}\text { New Iskan } \\
\text { Towers }\end{array}$ & 1 & 0 & 0 & 0 \\
\hline Shahan City & 1 & 0 & 0 & 0 \\
\hline Naz City & 2 & 1 & 1 & 1 \\
\hline Lana City & 1 & 0 & 0 & 0 \\
\hline Atlantic City & 1 & 0 & 0 & 0 \\
\hline Kurdistan City & 0 & 0 & 0 & 0 \\
\hline 92 Apartments & 1 & 0 & 1 & 0 \\
\hline $\begin{array}{c}\text { Kamarany } \\
\text { Apartments }\end{array}$ & 0 & 0 & 0 & 0 \\
\hline
\end{tabular}




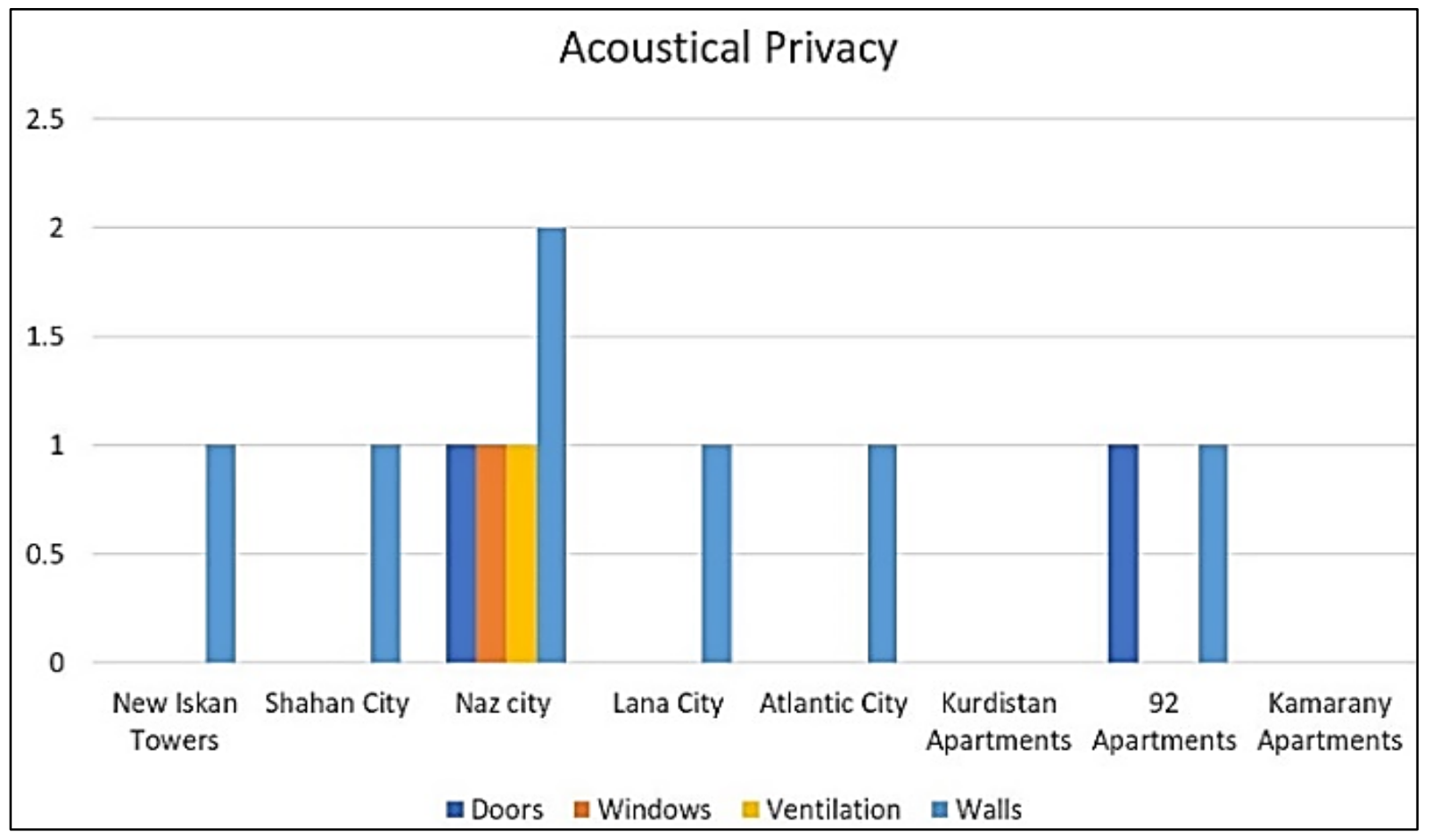

Figure 2. The results of Acoustical privacy

From the figure and table above, Kamarany Apartments and Kurdistan City have the poorest rating, rated at 0 out of all the buildings and for all the elements. From the table, it is apparent that acoustical privacy is poor in all the buildings because other than the walls in Naz City which are rated at 2 points, the rest of the elements are either 0 or 1 which shows a lack of consideration of acoustical privacy when building apartment blocks.

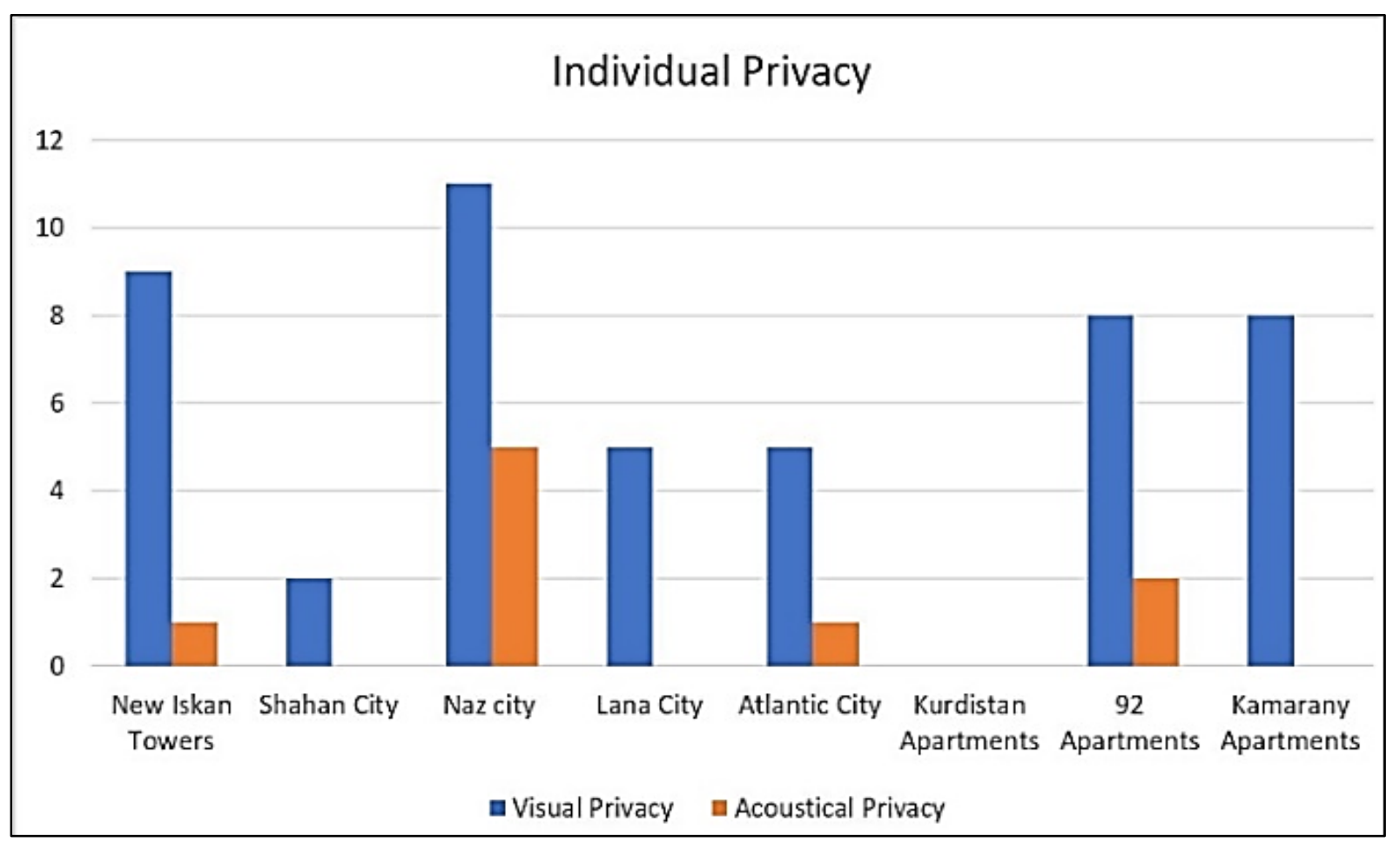

Figure 3. The results of individual privacy 
Table 4 and Figure 3 show the results of individual privacy for both the visual privacy and acoustical privacy.

Table 4. Individual privacy for the 8 buildings

\begin{tabular}{|c|c|c|}
\hline Projects & Visual & Acoustical \\
\hline New Iskan Towers & 9 & 1 \\
\hline Shahan City & 2 & 0 \\
\hline Naz City & 11 & 5 \\
\hline Lana City & 6 & 0 \\
\hline Atlantic City & 6 & 1 \\
\hline Kurdistan City & 0 & 0 \\
\hline 92 Apartments & 8 & 2 \\
\hline Kamarany Apartments & 1 & 0 \\
\hline
\end{tabular}

From these illustrations, New Iskan Towers scored 9 for the visual privacy and 1 point for the acoustical privacy. Shahan City has among the worst acoustical elements which mean lower acoustical privacy at 0 . Its visual privacy stood at 2 points. Naz City scored the best of both types of privacy.

The acoustical privacy stood at 5 while visual privacy stood at 11 . For Lana City, the acoustical privacy scored lower than the visual privacy at 0 against 6 points. The acoustical privacy of the Atlantic City scored lower than the visual privacy at 1 against 6 points. Out of the 8 buildings, Kurdistan City had the lowest privacy level for both types. Both acoustical and visual privacy scored 0 points each. 92 apartments scored high in visual privacy at 8 points while scoring low for the acoustical privacy at 2 points. Kamarany Apartments had the second lowest privacy level at 2 for acoustical privacy and 8 for visual privacy.

From these results, it can be seen that there is a wide variation between the individual privacy levels among the selected sample. For the visual privacy, Kurdistan City project has the worst of it scoring an average of 0 points. Naz City scored the highest at 11 points and this means that it offers the residents the best of the visual privacy. This is promoted mostly by the materials used in windows. The choice of materials highly influenced visual privacy. For example, the type of glasses fitted in windows determines how much light goes through into the building. Some windows can reflect light while others can let the light in such that people from one room can see what is happening in another. The same is true about the doors separating different rooms in the same apartment. On the other hand, acoustical privacy varies between the apartment buildings but not as much as the visual privacy. Shahan City, Lana City, Kurdistan City, and Kamarany Apartments all have the same (0) and the lowest level of acoustical privacy among all the assessed buildings. Like in visual privacy, Naz City had the highest score in acoustical privacy meaning that the acoustical elements in that building are made of the highest quality materials.

\subsection{Discussion}

There was a huge variation of privacy of the apartments between among the buildings for both acoustical and visual privacy. Even though the apartments selected had the same size, they had a different score when it comes to privacy, showing that the major determining factor of privacy of the apartments is the quality of the privacy elements for each type of privacy. For acoustical privacy, the privacy elements included insulation for the walls and openings. According to [10], walls prevent people from any form of invasive noises from the neighboring rooms which is achieved by having excellent insulation of the walls. In this case, the noises from a neighboring room cannot penetrate a room and the sounds from the same room cannot leak into the neighboring ones. Thus, a high degree of privacy is enhanced. Besides, Dimitroulopoulou [11] says that insulating ventilation is another premium activity which contributes much to a building's-maintained privacy level.

The current research findings show that the buildings whose ventilation and other openings are poorly insulated have the least of the acoustical privacy. As for the visual privacy, an even more disparity between the buildings was observed. While Naz City scored the highest with 11 points, Kurdistan City scored 0 points. This means that visual elements in Kurdistan City are way poorer than those of Naz City. These elements include windows, and doors to private rooms and other shared areas within a building. Fisher-Gewirtzman [12], in his research, found out that there is a strong correlation between the visibility measurements from openings and the visual privacy at the sitting room. Openings serve a crucial role in making sure that information is retained within a building and as Lai et al. [13] put it, a person can have a chance to be themselves in situations where privacy is upheld.

The question of what next with these kinds of disparities is a concern. There is a healthy concern on the differences between privacy on the three types of buildings. Both the local and national governments have not set minimum standards that should be met before a building is made. From the results, the major determinant of the quality of a building is the materials used in fittings during the interior designing. As such, the interior designers have less or no regulation concerning the type of materials to use and how to arrange buildings to achieve maximum privacy. As such, they have total autonomy regarding the quality of buildings. As [3] state, the relationship between an apartment's functional zones and the privacy of the users determines the internal layout of the buildings in Amman. This is the same case in Erbil where clients are the determinants of their privacy levels.

\section{Conclusion and Recommendations}

This study presented an analysis of privacy level among the Erbilian apartment buildings. The evaluation was done 
on acoustical and visual privacy of the various elements in the building such as openings and walls using a 3-point Likert scale. The researcher found out a huge variation in privacy levels with Naz City scoring the highest for both privacy types. Interior designers need to be creative enough on the choice of materials and positioning of walls and other enclosure elements to match them with the functionality of the apartment and make sure that people receive optimum privacy. The findings of this study are important because they could act as a guide for many players in the field such as residents, designers, policy-makers, and property developers. They will be able to understand the major features of a building that boost coziness of the enclosures while improving their social acceptability as a Muslim-dominant region.

From the study, there are various things that could be done to ensure that maximum individual privacy is achieved:

(1) Designers should consider alternative ways of ensuring that every person have received proper visual and acoustical privacy within their private places.

(2) The government should come up with regulations to govern the interior designers and make sure that there are particular standards on choice of materials and designs.

As a result, the researcher recommends that future researchers consider using multiple methods of data collection, both qualitative and quantitative. Besides, they may consider using different housing settings such as both urban and suburban areas to get more generalizable results. Finally, they should use different-sized apartment buildings with different interiors.

\section{REFERENCES}

[1] Büscher, M., Perng, S. Y., \& Liegl, M. "Privacy, Security, and Liberty: Ict in crises," in Censorship, Surveillance, and Privacy: Concepts, Methodologies, Tools, and Applications, IGI Global, 2019, pp. 199-217.

[2] Shabani, M. M., Tahir, M. M., Arjmandi, H., Abdullah, N. A. G., \& Usman, I. M. S. "Achieving Privacy in the Iranian Contemporary Compact Apartment through Flexible Design. Selected topics in power systems and remote sensing," in Selected Topics in Power Systems and Remote Sensing, WSEAS, 2010, pp. 285-296.

[3] Tomah, A.N., Ismail, H.B. and Abed, A. "The concept of privacy and its effects on residential layout and design: Amman as a case study." Habitat International, vol. 53, pp. 1-7. 2016. DOI: 10.1016/j.habitatint.2015.10.029

[4] Khandekar, R. P. "Interacting sets of contradictory human needs as drivers of human behavior." Indian Journal of Economics \& Business, vol. 11, no. 2, pp. 323-335, 2016.

[5] Malik, S., \& Mujahid, B. "Perception of House Design in Islam: Experiences from Saudi Arabia and Pakistan. Journal of Islamic Thought and Civilization, vol. 6, no. 2, pp. 53-76. 2016.

[6] De Paris, S.R. and Lopes, C.N.L. Housing flexibility problem: Review of recent limitations and solutions. Frontiers of Architectural Research, vol. 7, no. 1, pp. 80-91. 2018. DOI: $10.1016 /$ j.foar.2017.11.004

[7] Javanshir, S. Protection of Privacy in Designing of Residential Complexes Architecture and Its Effect on Constructive Relations among the Residents. Modern Applied Science, vol. 10, no. 1, pp. 103.2016.

[8] Khamenehzadeh, H. An Introduction to the Concept of Privacy and how it is Realized in the House Life-World1 Comparative Study in Pre-modern and Modern Iranian Houses. The Monthly Scientific Journal of Bagh-E Nazar, vol. 14, no. 49, pp. 33-44. 2016.

[9] Wahid, J., \& Khozaei, F. Visual privacy and residential facades in traditional and modern houses, case study: Houses hot-arid region of Iran. University Saings Malaysia, 11800 Penang, 2009

[10] Rasmussen, B. Sound insulation between dwellingsRequirements in building regulations in Europe. Applied Acoustics, vol. 71, no. 4, pp. 373-385. 2011 DOI: 10.1016/j.apacoust.2009.08.011

[11] Dimitroulopoulou, C. Ventilation in European dwellings: A review. Building and Environment, vol. 47, pp. 109-125. 2012. DOI: 10.1016/j.buildenv.2011.07.016

[12] Fisher-Gewirtzman, D. The association between perceived density in minimum apartments and spatial openness index three-dimensional visual analysis. Environment and Planning B: Urban Analytics and City Science, vol. 44, no. 4, pp. 764-795. 2017. DOI: $10.1177 / 0265813516657828$

[13] Lai, I. K. W., \& Shi, G. The impact of privacy concerns on the intention for continued use of an integrated mobile instant messaging and social network platform. International Journal of Mobile Communications, vol. 13, no. 6, pp. 641-669. 2015. 